\title{
Transcutaneous Measurement of Carbon Dioxide Tension During Extended Monitoring: Evaluation of Accuracy and Stability, and an Algorithm for Correcting Calibration Drift
}

\author{
David J Berlowitz PhD, Jo Spong PhD, Fergal J O’Donoghue MD PhD, Rob J Pierce MD, \\ Douglas J Brown MD, Donald A Campbell MD, Peter G Catcheside PhD, \\ Ian Gordon $\mathrm{PhD}$ and Peter D Rochford BApp Sci
}

\begin{abstract}
BACKGROUND: When polysomnography is indicated in a patient with a presumed sleep disorder, continuous monitoring of arterial carbon dioxide tension $\left(\mathrm{P}_{\mathrm{aCO}}\right)$ is desirable, especially if nocturnal hypoventilation is suspected. Transcutaneous $\mathrm{CO}_{2}$ monitors $\left(\mathrm{P}_{\mathrm{tcCO}}\right)$ provide a noninvasive correlate of $\mathbf{P}_{\mathrm{aCO}}$, but their accuracy and stability over extended monitoring have been considered inadequate for the diagnosis of hypoventilation. We examined the stability and accuracy of $\mathrm{P}_{\text {tcco }}$ measurements and the performance of a previously described linear interpolation technique designed to correct for calibration drift. METHODS: We compared the $\mathbf{P}_{\mathrm{tcCO}}$ values from 2 TINA TCM-3 monitors to $\mathrm{P}_{\mathrm{aCO}}$ values from arterial blood samples obtained at the beginning, every 15 min of the first hour, and then hourly over 8 hours of monitoring in 6 hemodynamically stable, male, intensive care patients (mean age $46 \pm 17 \mathrm{y})$. RESULTS: Time had a significant $(P=.002)$ linear effect on the $\mathrm{P}_{\mathrm{tcCO}}-\mathrm{P}_{\mathrm{aCO}}$ difference, suggesting calibration drift over the monitoring period. We found no differences between monitor type or interaction between time and monitor type. For the 2 monitors the uncorrected bias was $3.6 \mathrm{~mm} \mathrm{Hg}$ and the limits of agreement were -5.1 to $12.3 \mathrm{~mm} \mathrm{Hg}$. Our linear interpolation algorithm improved the bias and limits of agreement to 0.4 and -5.5 to $6.4 \mathrm{~mm} \mathrm{Hg}$, respectively. CONCLUSIONS: Following stabilization and correction for both offset and drift, $\mathrm{P}_{\mathrm{tcCO}}$ tracks $\mathrm{P}_{\mathrm{aCO}}$ with minimal residual bias over 8 hours of monitoring. Should future research confirm these findings, then interpolated $\mathrm{P}_{\mathrm{tcCO}}$ may have an increased role in detecting sleep hypoventilation and assessing the efficacy of treatment. Key words: carbon dioxide monitoring; polysomnography. [Respir Care 2011;56(4):442-448. (C) 2011 Daedalus Enterprises]
\end{abstract}

\section{Introduction}

When polysomnography is indicated in a patient with a presumed sleep disorder, continuous monitoring of arterial carbon dioxide tension $\left(\mathrm{P}_{\mathrm{aCO}_{2}}\right)$ is desirable, especially if nocturnal hypoventilation is suspected. Arterial blood sampling provides direct assessment of blood gas tensions, but it is an invasive, expensive, potentially sleep-disruptive measure, and provides only periodic data. In contrast, transcutaneous monitoring of $\mathrm{P}_{\mathrm{CO}_{2}}\left(\mathrm{P}_{\mathrm{tcCO}_{2}}\right)$ provides continuous data and is noninvasive. Transcutaneous $\mathrm{CO}_{2}$ monitors employ a skin-surface Stow-Severinghaus electrode to measure $\mathrm{CO}_{2}$ after heating and "arterialization" of the underlying tissue.

Although continuous $\mathrm{P}_{\mathrm{aCO}}$ measurement is desirable in the monitoring and treatment of hypoventilation, transcu- taneous $\mathrm{CO}_{2}$ monitoring is specifically not recommended for the quantification of hypoventilation during a sleep study. ${ }^{1}$ The limits of agreement between $\mathrm{P}_{\mathrm{aCO}}$ and $\mathrm{P}_{\mathrm{tcCO}}$ are considered too imprecise, particularly for extended monitoring where there is increased potential for electrode calibration drift. The methods used to quantify the change in $\mathrm{P}_{\mathrm{tcCO}_{2}}-\mathrm{P}_{\mathrm{aCO}}$ difference (electrode drift) during sleep are not well established, and previous research has not clearly established whether electrode drift is systematic and therefore amenable to quantification and correction. Despite these limitations, both the absolute $\mathrm{P}_{\mathrm{tcCO}_{2}}$ value and the $\mathrm{P}_{\mathrm{tcCO}_{2}}$ change during sleep are frequently reported as a clinical measure of both disease severity and treatment efficacy, particularly in studies of the outcome of noninvasive ventilation..$^{2-7}$ Although the minimum clinically important change that $\mathrm{P}_{\mathrm{tcCO}}$ monitoring aims to measure is 
not known, current consensus guidelines suggest that a rise of $\geq 10 \mathrm{~mm} \mathrm{Hg}$ in $\mathrm{P}_{\mathrm{aCO}_{2}}$ indicates sleep hypoventilation, ${ }^{1}$ and recent publications have suggested that $7.6 \mathrm{~mm} \mathrm{Hg}$ should be the accepted minimum clinically important difference between measured $\mathrm{P}_{\mathrm{aCO}_{2}}$ and $\mathrm{P}_{\mathrm{tcCO}_{2}}{ }^{8,9}$

To better understand the relationships between $\mathrm{P}_{\mathrm{tcCO}}$ and $\mathrm{P}_{\mathrm{aCO}_{2}}$, we assessed the stability and accuracy of $\mathrm{P}_{\mathrm{tcCO}_{2}}$ readings from 2 TINA TCM-3 monitors (Radiometer Medical, Brønshøj, Denmark) during extended monitoring, and determined the limits of agreement between $\mathrm{P}_{\mathrm{tcCO}_{2}}$ and $\mathrm{P}_{\mathrm{aCO}_{2}}$ measured from arterial blood, to characterize the monitors' electrode drift over 8 hours. In our institution the accuracy of the $\mathrm{P}_{\mathrm{tcCO}}$ values during a sleep study is established with an in vivo calibration against arterial blood samples taken at the start of the monitoring period. Any observed $\mathrm{P}_{\mathrm{tcCO}_{2}}-\mathrm{P}_{\mathrm{aCO}}$ difference thereafter is assumed to behave as a fixed offset and to remain constant. A second arterial sample is taken at the end of the monitoring period, and the observed change in the $\mathrm{P}_{\mathrm{tcCO}}-\mathrm{P}_{\mathrm{aCO}}$ difference is assumed to reflect electrode drift. To assess the validity of this procedure we also assessed the utility of the previously published methods for correction of offset and electrode drift in $\mathrm{P}_{\mathrm{tcCO}_{2}}$ values. ${ }^{10}$

\section{Methods}

This research was conducted at Austin Hospital, Heidelberg, Australia. The study protocol was approved by the

David J Berlowitz PhD, Jo Spong PhD, Fergal J O'Donoghue MD PhD, Rob J Pierce MD, and Peter D Rochford BApp Sci are affiliated with the Institute for Breathing and Sleep, Austin Hospital, Heidelberg, Australia. Douglas J Brown MD is also affiliated with the Victorian Spinal Cord Service, Austin Hospital, Heidelberg, Australia. Drs Berlowitz and O'Donoghue are also affiliated with Department of Medicine, Dentistry and Health Sciences, University of Melbourne, Melbourne, Australia. Donald A Campbell MD is affiliated with the Department of Medicine, Monash University, Clayton, Australia. Peter G Catcheside PhD is affiliated with the Adelaide Institute for Sleep Health, Repatriation General Hospital, Daw Park, Australia; the Department of Medicine, Flinders University, Bedford Park, Australia; and the Discipline of Physiology, School of Molecular and Biomedical Sciences, University of Adelaide, Adelaide, Australia. Ian Gordon $\mathrm{PhD}$ is affiliated with the Statistical Consulting Centre, The University of Melbourne, Melbourne, Australia.

This research was partly supported by a Dora Lush Scholarship from the National Health and Medical Research Council of Australia, and a grant from the Physiotherapy Research Foundation of Australia.

The authors have disclosed no conflicts of interest.

Supplementary material related to this paper is available at http://www. rcjournal.com.

Correspondence: David J Berlowitz $\mathrm{PhD}$, Institute for Breathing and Sleep, Bowen Centre, Austin Hospital, PO Box 5555, Heidelberg, Victoria, 3084, Australia. E-mail: david.berlowitz@austin.org.au.

DOI: $10.4187 /$ respcare.00454
Human Ethics Committee of the Austin and Repatriation Medical Centre. All patients or their authorized representatives gave informed consent.

\section{Subjects}

It was considered unethical to conduct arterial puncture in otherwise healthy people undergoing a routine sleep study, so we recruited stable patients in our intensive care unit (ICU) to serve as a model for people in the sleep laboratory. We selected ICU patients because they typically have an indwelling arterial catheter. The potential impact of tissue hypoperfusion on the results was minimized by excluding patients on inotropic support, with temperature greater than $37.0^{\circ} \mathrm{C}$, or who just had cardiac arrest or surgery.

\section{Transcutaneous Carbon Dioxide Monitor}

We measured $\mathrm{P}_{\mathrm{tcCO}_{2}}$ simultaneously with 2 TINA TCM-3 monitors (Monitor 1 and Monitor 2). The TCM-3 monitor employs a dual transcutaneous carbon dioxide and oxygen electrode. We used a new transcutaneous electrode membrane for each study. The electrodes were re-membraned 12-24 hours prior to each study. The probes were heated to $43^{\circ} \mathrm{C}$ and the analog outputs recorded continuously on chart paper and were calibrated with the devices' 1 -volt internal test signal.

The $\mathrm{P}_{\mathrm{tcCO}_{2}}$ monitors were calibrated according to the manufacturer's instructions, using a one-point dry-gas calibration with $5 \% \mathrm{CO}_{2}$. The skin was shaved if required, cleansed with alcohol, and dried. The $\mathrm{P}_{\mathrm{tcCO}_{2}}$ electrodes were positioned approximately $2 \mathrm{~cm}$ apart on the patient's anterior chest wall, and attached with their respective adhesive rings and contact solutions. Additional tape was applied to secure the electrodes and minimize the risk of movement or dislodgment. The usual nursing, medical, and physiotherapy care of the patients was not altered during the monitoring period.

\section{Arterial Blood Sampling}

Arterial blood samples were obtained via a 3-way tap connected to the arterial line. Arterial samples were taken at the beginning, every $15 \mathrm{~min}$ for the first hour, and then hourly during the monitoring period. The clinical care of participants was managed by the usual ICU care team, but attention was given to ensure that the participants had no change in ventilation made immediately prior to any sample being drawn. Furthermore, all samples were drawn during periods of steady-state breathing and recording (defined as no $\mathrm{P}_{\mathrm{tcCO}_{2}}$ change $>2 \mathrm{~mm} \mathrm{Hg}$ for at least $3 \mathrm{~min}$ and no apparent respiratory instability associated with rolling over or with gross body movements). We recorded the 
time of each arterial sample and the $\mathrm{P}_{\mathrm{tcCO}}$ value at that time of the arterial sample.

The accuracy of the blood-gas analyzer (ABL500, Radiometer Medical, Brønshøj, Denmark) was confirmed with standard quality-control solutions. Whole-blood tonometry was also performed twice during each study period to verify the accuracy of the blood-gas analyzer. The arterial blood samples were immediately placed in an ice-andwater slurry, and analyzed (in duplicate) within $20 \mathrm{~min}$ of drawing. If the $2 \mathrm{P}_{\mathrm{aCO}_{2}}$ values were more than $1 \mathrm{~mm} \mathrm{Hg}$ different, a third $\mathrm{P}_{\mathrm{aCO}}$ measurement was made. We used the average of the 2 closest $\mathrm{P}_{\mathrm{aCO}}$ values.

\section{Method for Correcting Electrode Drift and Offset}

For each patient we matched the $\mathrm{P}_{\mathrm{aCO}}$ values obtained 15 min after electrode application with the corresponding $\mathrm{P}_{\mathrm{tcCO}_{2}}$ and used the difference as the initial measurement of electrode offset. The $\mathrm{P}_{\mathrm{aCO}_{2}}$ measurements at 8 hours were used as the final in vivo calibration points for the simultaneous $\mathrm{P}_{\mathrm{tcCO}_{2}}$ measurement. We used changes in that difference as an estimate of electrode calibration drift. We corrected the $\mathrm{P}_{\mathrm{tcCO}_{2}}$ values by subtracting the baseline offset alone, and then by subtracting both the baseline offset and the drift over the 8 hours. ${ }^{10} \mathrm{~A}$ spreadsheet example of the correction process is available in the supplementary materials at http://www.rcjournal.com.

\section{Statistical Analysis}

Given the potential for variable or systematic $\mathrm{P}_{\mathrm{tcCO}}{ }_{2}^{-}$ $\mathrm{P}_{\mathrm{aCO}_{2}}$ differences, we employed several strategies to analyze $\mathrm{P}_{\mathrm{tcCO}}$ offset and drift. We analyzed for offset and drift with linear regression of each subject's $\mathrm{P}_{\mathrm{tcCO}_{2}}$ recording. We analyzed the $\mathrm{P}_{\mathrm{tcCO}}-\mathrm{P}_{\mathrm{aCO}}$ differences and patterns of $\mathrm{P}_{\mathrm{tcCO}_{2}}$ change (drift) in the group data with repeatedmeasures analysis of variance, incorporating polynomial trend analysis to investigate systematic linear versus higher-order polynomial effects over time. We made post hoc pair-wise comparisons of mean differences at each time, incorporating a Bonferroni correction for multiple comparisons. We examined the benefit of using corrected values with a linear mixed-effects model analysis, ${ }^{11}$ with the $\mathrm{P}_{\mathrm{tcCO}}-\mathrm{P}_{\mathrm{aCO}}$ difference as the response, subject as a random effect with separate intercept, and monitor (Monitor 1 or Monitor 2) and correction type (uncorrected, corrected for baseline only, and corrected for both baseline and drift) as factors. We conducted the analyses with statistics software (PASW Statistics 18.0, SPSS, Chicago, Illinois), and we ran the fully saturated model first, followed by removal of nonsignificant interaction terms. We also determined instrument bias (average) and limits of agreement (1.96 standard deviations) in the group data, according to the methods of Bland and Altman. ${ }^{12}$ Results are presented
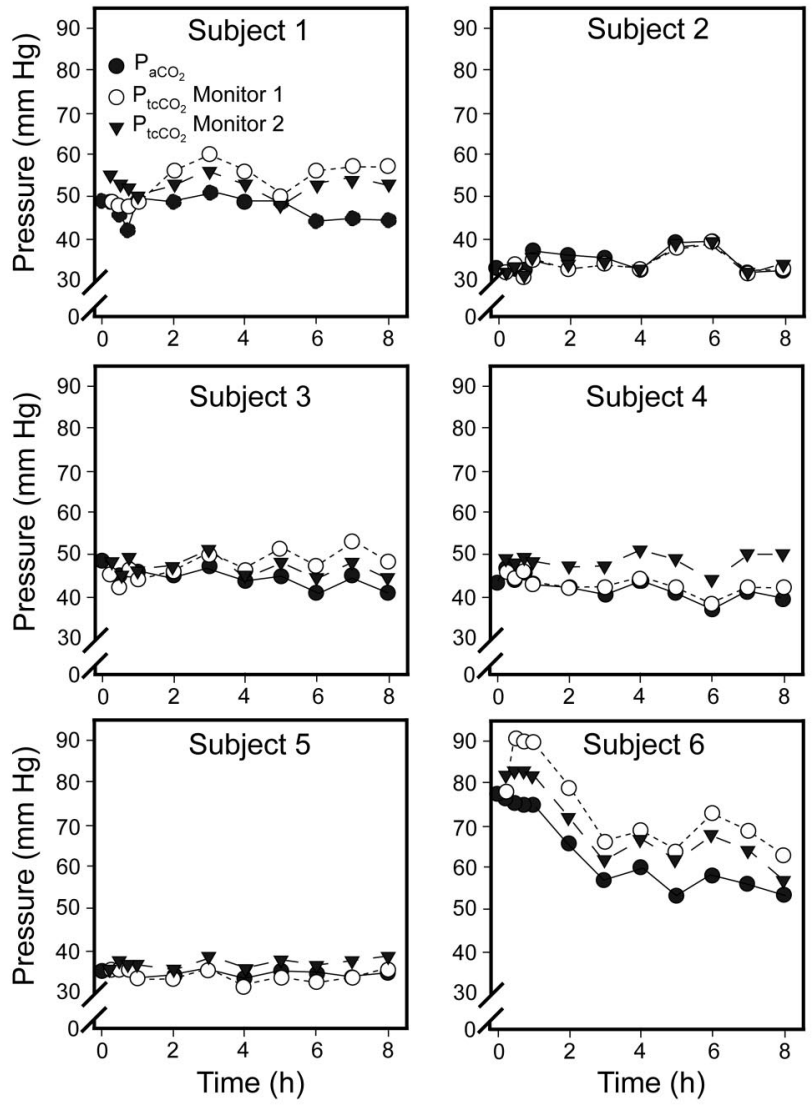

Fig. 1. $\mathrm{P}_{\mathrm{aCO}_{2}}$ and transcutaneously measured $\mathrm{P}_{\mathrm{CO}_{2}}\left(\mathrm{P}_{\mathrm{tcCO}_{2}}\right)$ measured with $2 \mathrm{P}_{\mathrm{tcCO}_{2}}$ monitors, over 8 hours in 6 subjects.

as mean $\pm \mathrm{SD}$ unless otherwise indicated. $P<.05$ was regarded as significant.

\section{Results}

We recruited 6 male patients (mean age $46 \pm 17 \mathrm{y}$, range 26-72 y), whose diagnoses were trauma, post-neurosurgery, C3/4 spinal injury, C4/5 spinal injury, subarachnoid hemorrhage, and asthma. Four subjects were intubated and sedated to various degrees, but none were pharmacologically paralyzed. The mean $\mathrm{P}_{\mathrm{aCO}}$ of all 72 arterial samples was $45.6 \pm 12.8 \mathrm{~mm} \mathrm{Hg}$ (range 31.9 $77.7 \mathrm{~mm} \mathrm{Hg}$ ). All samples were drawn at the scheduled sample times, and all the recording periods were 8 hours. We found no cutaneous irritation or burning associated with the electrodes.

Figure 1 shows the $\mathrm{P}_{\mathrm{aCO}_{2}}$ and $\mathrm{P}_{\mathrm{tcCO}}$ values, and Figure 2 shows the $\mathrm{P}_{\mathrm{tcCO}}-\mathrm{P}_{\mathrm{aCO}}$ differences. Table 1 shows the minimum and maximum $\mathrm{P}_{\mathrm{aCO}}$, drift, and intercept data, and the linear regression correlation coefficients. In the individual recordings, statistically significant baseline offset and linear drift were common: each affected 5 of 12 records (see Table 1), and 4 of 6 patients had drift of 


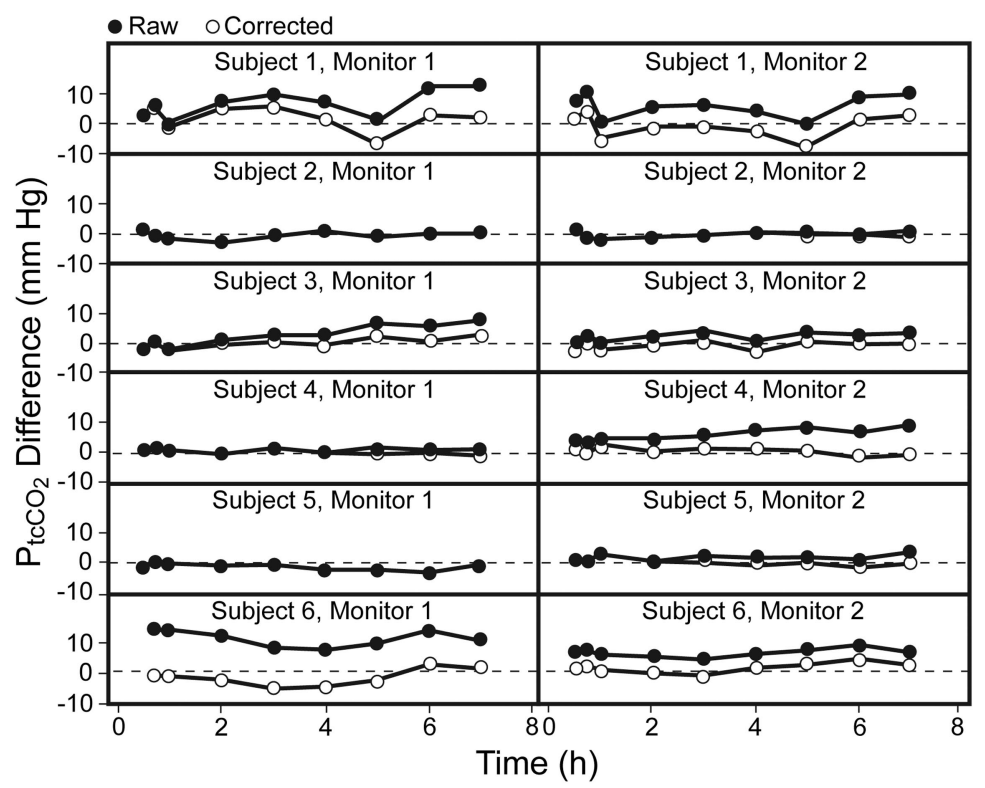

Fig. 2. Raw and corrected differences between $\mathrm{P}_{\mathrm{acO}}$ and transcutaneously measured $\mathrm{P}_{\mathrm{CO}_{2}}\left(\mathrm{P}_{\mathrm{tcCO}}\right)$ measured with $2 \mathrm{P}_{\text {tcco }}$ monitors, over 8 hours in 6 subjects.

Table 1. $\quad \mathrm{P}_{\mathrm{aCO}_{2}}$, Drift, Intercept, and Slope Data

\begin{tabular}{|c|c|c|c|c|c|c|c|c|c|c|c|}
\hline \multirow[b]{2}{*}{ Subject } & \multirow[b]{2}{*}{ Diagnosis } & \multicolumn{2}{|c|}{$\begin{array}{c}\mathrm{P}_{\mathrm{aCO}_{2}} \\
(\mathrm{~mm} \mathrm{Hg})\end{array}$} & \multicolumn{2}{|c|}{$\begin{array}{c}\text { Drift* } \\
(\mathrm{mm} \mathrm{Hg})\end{array}$} & \multicolumn{2}{|c|}{$\begin{array}{l}\text { Intercept } \dagger \\
(\mathrm{mm} \mathrm{Hg})\end{array}$} & \multicolumn{2}{|c|}{$\begin{array}{c}\text { Slope } \dagger \\
(\mathrm{mm} \mathrm{Hg} / \mathrm{h})\end{array}$} & \multicolumn{2}{|c|}{$r^{2} \neq$} \\
\hline & & Min & Max & Monitor 1 & Monitor 2 & Monitor 1 & Monitor 2 & Monitor 1 & Monitor 2 & Monitor 1 & Monitor 2 \\
\hline 1 & Multiple trauma & 42.1 & 50.9 & $12.3 \S$ & 2.3 & $2.1 \pm 2.1$ & $4.3 \pm 2.2$ & $1.2 \pm 0.5 \|$ & $0.3 \pm 0.5$ & $0.483 \|$ & 0.056 \\
\hline 2 & Post-neurosurgery & 31.9 & 39.5 & 0.3 & 1.3 & $-1.5 \pm 0.7$ & $-1.3 \pm 0.6$ & $0.2 \pm 0.2$ & $0.2 \pm 0.1$ & 0.160 & 0.273 \\
\hline 3 & C3/4 spinal injury & 40.7 & 48.3 & $7.1 \S$ & 0.1 & $-1.8 \pm 0.7 \|$ & $1.5 \pm 0.7$ & $1.3 \pm 0.2 \|$ & $0.3 \pm 0.2$ & $0.905 \|$ & 0.245 \\
\hline 4 & C4/5 spinal injury & 36.7 & 46.5 & 3.1 & $8.1 \S$ & $0.2 \pm 0.3$ & $3.9 \pm 0.4 \|$ & $0.2 \pm 0.1 \|$ & $0.8 \pm 0.1 \|$ & $0.539 \|$ & $0.913 \|$ \\
\hline 5 & Subarachnoid hemorrhage & 33.8 & 37.0 & 0.6 & 3.6 & $-0.6 \pm 0.6$ & $1.4 \pm 0.4 \|$ & $0.0 \pm 0.1$ & $0.3 \pm 0.1 \|$ & 0.003 & $0.450 \|$ \\
\hline 6 & Asthma & 53.5 & 77.6 & $7.7 \S$ & -2.3 & $14.4 \pm 1.4 \|$ & $7.5 \pm 1.1 \|$ & $-0.5 \pm 0.3$ & $-0.1 \pm 0.2$ & 0.269 & 0.033 \\
\hline
\end{tabular}

$>4 \mathrm{~mm} \mathrm{Hg}$ in at least one monitor. In the group data there was a significant positive intercept $(P=.01)$ and linear effect of time on the $\mathrm{P}_{\mathrm{tcCO}}-\mathrm{P}_{\mathrm{aCO}}$ difference $(P=.002)$, indicating systematic bias and drift, increasing on average from $1.7 \pm 1.6 \mathrm{~mm} \mathrm{Hg}$ at baseline to $5.4 \pm 3.5 \mathrm{~mm} \mathrm{Hg}$ at the conclusion of the recording period. No higher-order polynomial effects were observed, which supports the finding that the drift was predominantly linear. There was no difference in overall performance between the 2 monitors in raw $\mathrm{P}_{\mathrm{tcCO}}-\mathrm{P}_{\mathrm{aCO}_{2}}$ difference scores $(P=.82)$ and no significant interaction between time and monitor type $(P=.97)$.

Offset and drift correction decreased the bias and limits of agreement of the $\mathrm{P}_{\mathrm{tcCO}}-\mathrm{P}_{\mathrm{aCO}}$ difference (see Figs. 2 and 3). Mixed-model analysis showed statistically significant main effects of time $(P<.001)$, monitor $(P=.01)$, and correction type $(P<.001)$, and a significant monitorby-correction interaction $(P=.01)$, but no further interaction effects. The monitor main and interaction effects indicated that, overall, Monitor 1 had greater bias than Monitor $2(2.4 \pm 1.5 \mathrm{~mm} \mathrm{Hg}$ vs $1.6 \pm 1.5 \mathrm{~mm} \mathrm{Hg})$, $P=.01)$, in post hoc tests, revealing greater residual bias in Monitor 1 than in Monitor 2 with a baseline correction alone, but no further differences between the monitors. The correction-type effect showed incremental reductions in $\mathrm{P}_{\mathrm{tcCO}}-\mathrm{P}_{\mathrm{aCO}}$ difference with each correction, and that the combined correction was superior. Overall bias was reduced by $1.7 \pm 1.1 \mathrm{~mm} \mathrm{Hg}$ with baseline correction 

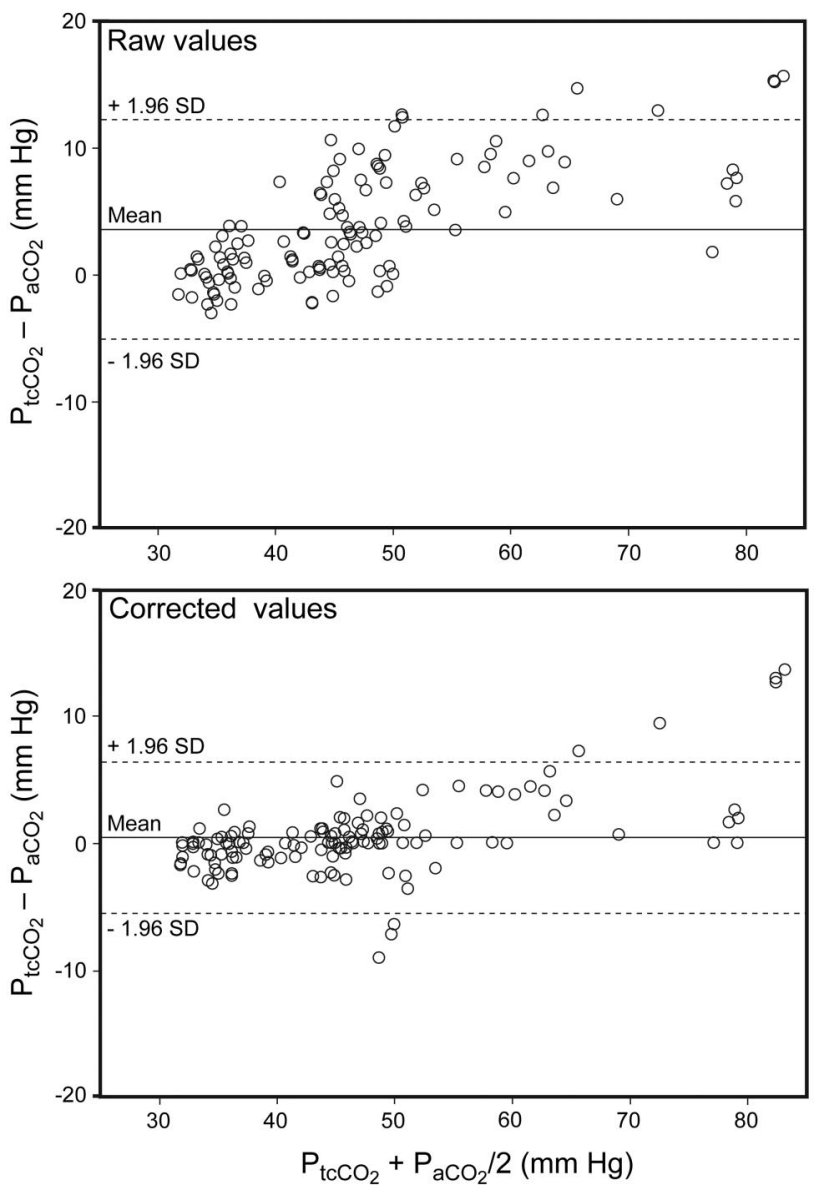

Fig. 3. Bland-Altman plot of raw and corrected (interpolated) $\mathrm{P}_{\mathrm{aCO}_{2}}$ and transcutaneously measured $\mathrm{P}_{\mathrm{CO}_{2}}\left(\mathrm{P}_{\mathrm{tcCO}_{2}}\right)$ (combined $\mathrm{P}_{\mathrm{tcCO}}$ values from the 2 monitors). Before correction the bias is $4 \mathrm{~mm} \mathrm{Hg}$ and the limits of agreement are -9 to $9 \mathrm{~mm} \mathrm{Hg}$. After correction the bias is less than $1 \mathrm{~mm} \mathrm{Hg}$, and the limits of agreement are -6 to $6 \mathrm{~mm} \mathrm{Hg}$.

alone $(P=.001)$, and by a further $1.5 \pm 0.9 \mathrm{~mm} \mathrm{Hg}$ with combined baseline and drift correction $(P<.001$, Table 2).

\section{Discussion}

We have demonstrated that while $\mathrm{P}_{\mathrm{tcCO}_{2}}$ monitoring can track trends in $\mathrm{P}_{\mathrm{aCO}}$ during an extended (8-hour) monitoring period, significant electrode drift is common, but tends to be linear when $\mathrm{P}_{\mathrm{tcCO}}$ is stable (ie, no change $>2 \mathrm{~mm} \mathrm{Hg}$ over the preceding $3 \mathrm{~min}$ ). Consequently, a 2-point in vivo calibration using the $\mathrm{P}_{\mathrm{tcCO}}$ offset and drift, versus arterial $\mathrm{P}_{\mathrm{aCO}}$ measurements at the beginning and end of recording, allowed for substantial compensation for $\mathrm{P}_{\mathrm{tcCO}_{2}}$ drift. Simple baseline adjustment alone reduced bias, but ignores significant drift, and was inferior to 2-point baseline and drift correction. While the requirement for arterial blood measurements at the beginning and end of extended recording may limit the clinical utility of this method, more frequent arterial sampling is often impractical, particularly in a sleep laboratory setting, where $\mathrm{P}_{\mathrm{tcCO}_{2}}$ monitoring is common and potentially most useful.

We confirm that the accuracy and the agreement of the monitors was too imprecise for uncorrected $\mathrm{P}_{\mathrm{tcCO}_{2}}$ measurements to substitute directly for $\mathrm{P}_{\mathrm{aCO}}$ in adults, as has been previously described.4,13-18 The reasons for the observed differences between $\mathrm{P}_{\mathrm{aCO}}$ and $\mathrm{P}_{\mathrm{tcCO}}$ have previously been reviewed. ${ }^{19}$ However, we would attest that the aim of continuous $\mathrm{CO}_{2}$ measurement during extended sleep monitoring is to detect sleep-related changes that suggest the presence or adequate control of hypoventilation, rather than as a direct measure of $\mathrm{P}_{\mathrm{aCO}}$ per se (ie, monitoring changes during sleep, rather than measuring absolute values), so noninvasive devices that can detect change over an extended monitoring period with sufficient accuracy and minimal artifactual drift have substantial clinical utility.

\section{Limitations}

The generalizability of our findings is limited by our use of only one model of $\mathrm{P}_{\mathrm{tcCO}_{2}}$ monitor and the small number and type of patients studied. However, the performance of the TINA-TCM3 monitors was similar to that in other studies that used the TINA-TCM3 monitor ${ }^{2,4}$ suggesting that our results are valid for this device. Although we studied only 6 participants, the $\mathrm{P}_{\mathrm{aCO}_{2}}$ values ranged widely, from $31.9 \mathrm{~mm} \mathrm{Hg}$ to $77.6 \mathrm{~mm} \mathrm{Hg}$, and that wide range has been suggested as desirable in studies such as this. ${ }^{4}$ As shown in Figure 3 and in previous literature, ${ }^{13,15,20}$ the correlation between $\mathrm{P}_{\mathrm{aCO}_{2}}$ and $\mathrm{P}_{\mathrm{tcCO}_{2}}$ decreases as $\mathrm{P}_{\mathrm{aCO}}$ increases, particularly beyond $50 \mathrm{~mm} \mathrm{Hg}$, which reinforces the need for both offset and drift correction to maximize the utility of a continuous $\mathrm{P}_{\mathrm{tcCO}_{2}}$ trace, and it cautions against $\mathrm{P}_{\mathrm{tcCO}}$ as the sole method of quantifying severe hypoventilation. ${ }^{1}$ Our study therefore both demonstrates the utility of the offset and drift correction method and identifies circumstances where its performance may be compromised.

We used ICU patients as "models" of patients in a sleep laboratory, because we could not conduct arterial punctures in otherwise well sleep patients. Additionally, our experience suggested that taking arterial blood samples from sleeping participants typically resulted in arousal from sleep, large changes in ventilation, and, thus, non-steadystate comparisons of transcutaneous and arterial measurements. While all care was taken to include participants who best modeled the "sleep patient," future validation studies of the interpolation method with multiple simultaneous measurements over an extended monitoring period should be with sleeping patients who experience a wide range of $\mathrm{P}_{\mathrm{aCO}}$. 
Table 2. Effect of Offset and Drift Correction on the Bias and Limits of Agreement* of Transcutaneously Measured $\mathrm{P}_{\mathrm{CO}_{2}}$

\begin{tabular}{|c|c|c|c|c|c|c|}
\hline & \multicolumn{2}{|c|}{$\begin{array}{l}\text { Uncorrected } \\
(\mathrm{mm} \mathrm{Hg})\end{array}$} & \multicolumn{2}{|c|}{$\begin{array}{l}\text { Baseline Corrected } \\
(\mathrm{mm} \mathrm{Hg})\end{array}$} & \multicolumn{2}{|c|}{$\begin{array}{l}\text { Baseline and Drift Corrected } \\
(\mathrm{mm} \mathrm{Hg})\end{array}$} \\
\hline & Mean \pm SD Bias & $\begin{array}{l}\text { Limits of } \\
\text { Agreement }\end{array}$ & Mean \pm SD Bias & $\begin{array}{l}\text { Limits of } \\
\text { Agreement }\end{array}$ & Mean \pm SD Bias & $\begin{array}{l}\text { Limits of } \\
\text { Agreement }\end{array}$ \\
\hline Monitor 1 & $3.3 \pm 5.3$ & -7.1 to 13.7 & $3.0 \pm 4.8$ & -6.5 to 12.5 & $0.9 \pm 3.7$ & -6.3 to 8.0 \\
\hline Monitor 2 & $3.9 \pm 3.3$ & -2.7 to 10.4 & $0.9 \pm 2.7 \dagger$ & -4.3 to 6.1 & $0.0 \pm 2.2$ & -4.3 to 4.3 \\
\hline Combined data & $3.6 \pm 4.4$ & -5.1 to 12.3 & $1.9 \pm 4.0 \ddagger$ & -6.0 to 9.8 & $0.4 \pm 3.0 \$ \S$ & -5.5 to 6.4 \\
\hline \multicolumn{7}{|c|}{ 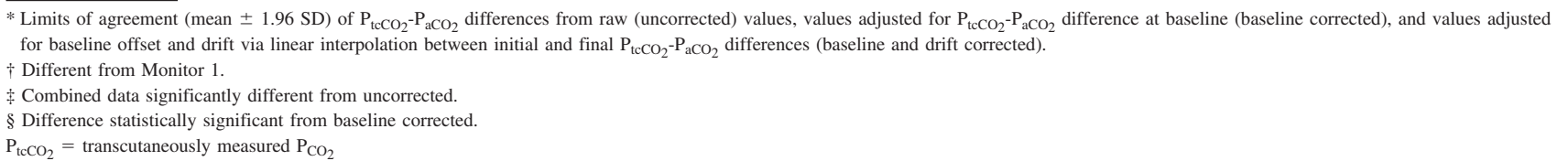 } \\
\hline
\end{tabular}

Similar to transcutaneous carbon dioxide monitoring, end-tidal carbon dioxide $\left(\mathrm{P}_{\mathrm{ETCO}_{2}}\right)$ monitoring is a noninvasive method of continuously measuring carbon dioxide over an extended period. In healthy awake individuals, $\mathrm{P}_{\mathrm{ETCO}_{2}}$ is essentially equivalent to alveolar (and thus arterial) carbon dioxide values. However, data obtained during sleep indicated that $\mathrm{P}_{\mathrm{ETCO}}$ is insufficiently accurate for diagnostic use in the able-bodied because of the normal reduction in tidal volume and the associated difficulty in detecting an alveolar plateau in the $\mathrm{P}_{\mathrm{ETCO}_{2}}$ trace. ${ }^{20}$ Furthermore, patients with underlying lung disease and associated ventilation-perfusion inhomogeneity are likely to have additional dissociations between $\mathrm{P}_{\mathrm{ETCO}}$ and alveolar $\mathrm{CO}_{2}$. The American Academy of Sleep Medicine guidelines ${ }^{1}$ provide a recommendation level of D for $\mathrm{P}_{\mathrm{ETCO}_{2}}$ monitoring, and $\mathrm{C}$ for $\mathrm{P}_{\mathrm{tcCO}_{2}}$, and recommend that further research examine the ability of $\mathrm{P}_{\mathrm{tcCO}_{2}}$ to monitor change over extended periods. Those guidelines make no recommendation for further investment in $\mathrm{P}_{\mathrm{ETCO}_{2}}$ monitoring during sleep. Unfortunately, there is currently no ideal noninvasive measure of $\mathrm{CO}_{2}$ during sleep; in the present study we sought to explore whether the imperfect transcutaneous measurement can be made better through the addition of arterial blood sampling at the start and end of the recording period, and by offset and drift correction

While the detection of a $\mathrm{P}_{\mathrm{aCO}_{2}}$ difference of $7.6 \mathrm{~mm} \mathrm{Hg}$ has been suggested to be the clinically important threshold value, 8,9 that value is arbitrary and may not represent a clinically relevant limit. There appear to be no published, prospective data that relate a given change in $\mathrm{P}_{\mathrm{aCO}_{2}}$ (much less $\mathrm{P}_{\mathrm{tcCO}_{2}}$ ) to clinical decision making or to clinical outcomes. However, Rodriguez et al demonstrated good discriminant ability of a $\mathrm{P}_{\mathrm{tcCO}_{2}}$ monitor to detect a $7.6 \mathrm{~mm} \mathrm{Hg}$ threshold, ${ }^{18}$ and the American Academy of Sleep Medicine recommendations suggest that an overnight $\mathrm{P}_{\mathrm{aCO}_{2}}$ change of $\geq 10 \mathrm{~mm} \mathrm{Hg}$ indicates sleep hypoventilation. ${ }^{1}$ Therefore, although $7.6 \mathrm{~mm} \mathrm{Hg}$ may be arbitrary, it is a pragmatic limit that may be expected to be sensitive to clinically important change. However, longitudinal studies of a $7.6 \mathrm{~mm} \mathrm{Hg}$ change are required to confirm the effect of that difference on clinical decision making or patient outcomes.

\section{Conclusions}

Even though $\mathrm{P}_{\mathrm{tcCO}_{2}}$ has been considered inadequate for the diagnosis or the measurement of response to treatment of hypoventilation, it is used clinically and frequently reported as a measurement of both disease severity and treatment efficacy, particularly in studies of noninvasive ventilation. $^{2-7}$ This apparent contradiction suggests that clinicians use the $\mathrm{P}_{\text {tcCO}}$ signal, most likely in combination with other polysomnographic traces and periodic $\mathrm{P}_{\mathrm{aCO}_{2}}$ measurements, in the care of their patients, while acknowledging that it may not accurately represent $\mathrm{P}_{\mathrm{aCO}_{2}}$ at all times.

The present study provides the first prospective evidence that if corrections are implemented for both offset and drift, $\mathrm{P}_{\mathrm{tcCO}_{2}}$ tracks $\mathrm{P}_{\mathrm{aCO}}$ with minimal residual bias over 8 hours of monitoring. Further research, particularly in subjects with less stable ventilation during sleep, is required before $\mathrm{P}_{\text {tcCO}}$ is likely to be recommended for routine clinical use. However, should further research support that recommendation, the present results suggest that the bias and limits of agreement of the interpolated $\mathrm{CO}_{2}$ values are likely to be sufficiently precise to both detect sleep hypoventilation and to assess the efficacy of treatment.

\section{REFERENCES}

1. Sleep-related breathing disorders in adults: recommendations for syndrome definition and measurement techniques in clinical research. The Report of an American Academy of Sleep Medicine Task Force. Sleep 1999;22(5):667-689.

2. Rosner V, Hannhart B, Chabot F, Polu J. Validity of transcutaneous oxygen/carbon dioxide pressure measurement in the monitoring of 


\section{Transcutaneous Measurement of Carbon Dioxide Tension}

mechanical ventilation in stable chronic respiratory failure. Eur Respir J 1999;13(5):1044-1047.

3. Cox M, Kemp R, Anwar S, Athey V, Aung T, Moloney ED. Noninvasive monitoring of $\mathrm{CO}_{2}$ levels in patients using NIV for AECOPD. Thorax 2006;61(4):363-364.

4. Cuvelier A, Grigoriu B, Molano LC, Muir J-F. Limitations of transcutaneous carbon dioxide measurements for assessing long-term mechanical ventilation. Chest 2005;127(5):1744-1748.

5. Ward S, Chatwin M, Heather S, Simonds AK. Randomised controlled trial of noninvasive ventilation (NIV) for nocturnal hypoventilation in neuromuscular and chest wall disease patients with daytime normocapnia. Thorax 2005;60(12):1019-1024.

6. Guo YF, Sforza E, Janssens JP. Respiratory patterns during sleep in obesity-hypoventilation patients treated with nocturnal pressure support: a preliminary report. Chest 2007;131(4):1090-1099.

7. Meecham Jones DJ, Paul EA, Jones PW, Wedzicha JA. Nasal pressure support ventilation plus oxygen compared with oxygen therapy alone in hypercapnic COPD. Am J Respir Crit Care Med 1995; 152(2):538-544

8. Bolliger D, Steiner LA, Kasper J, Aziz OA, Filipovic M, Seeberger MD. The accuracy of noninvasive carbon dioxide monitoring: A clinical evaluation of 2 transcutaneous systems. Anaesthesia 2007; 62(4):394-399.

9. Bendjelid K, Schutz N, Stotz M, Gerard I, Suter PM, Romand JA. Transcutaneous $\mathrm{P}_{\mathrm{CO}_{2}}$ monitoring in critically ill adults: clinical evaluation of a new sensor. Crit Care Med 2005;33(10):2203-2206.

10. O'Donoghue FJ, Catcheside PG, Ellis EE, Grunstein RR, Pierce RJ, Rowland LS, et al. Sleep hypoventilation in hypercapnic COPD: prevalence and associated factors. Eur Respir J 2003;21(6):977-984.

11. Laird NM, Ware JH. Random-effects models for longitudinal data. Biometrics 1982;38(4):963-974.
12. Bland JM, Altman DG. Statistical methods for assessing agreement between 2 methods of clinical measurement. Lancet 1986;1(8476): 307-310.

13. Janssens JP, Howarth-Frey C, Chevrolet JC, Abajo B, Rochat T. Transcutaneous $\mathrm{P}_{\mathrm{CO}_{2}}$ to monitor noninvasive mechanical ventilation in adults: assessment of a new transcutaneous $\mathrm{P}_{\mathrm{CO}_{2}}$ device. Chest 1998;113(3):768-773.

14. Janssens JP, Laszlo A, Uldry C, Titelion V, Picaud C, Michel JP. Noninvasive (transcutaneous) monitoring of $\mathrm{P}_{\mathrm{CO}_{2}}\left(\mathrm{TcP}_{\mathrm{CO}_{2}}\right)$ in older adults. Gerontology 2005;51(3):174-178.

15. Janssens JP, Perrin E, Bennani I, de Muralt B, Titelion V, Picaud C. Is continuous transcutaneous monitoring of $\mathrm{P}_{\mathrm{CO}_{2}}\left(\mathrm{TcP}_{\mathrm{CO}_{2}}\right)$ over $8 \mathrm{~h}$ reliable in adults? Respir Med 2001;95(5):331-335.

16. Nishiyama T, Nakamura S, Yamashita K. Effects of the electrode temperature of a new monitor, TCM4, on the measurement of transcutaneous oxygen and carbon dioxide tension J Anesth 2006;20(4): 331-334.

17. Senn O, Clarenbach CF, Kaplan V, Maggiorini M, Bloch KE. Monitoring carbon dioxide tension and arterial oxygen saturation by a single earlobe sensor in patients with critical illness or sleep apnea. Chest 2005;128(3):1291-1296.

18. Rodriguez P, Lellouche F, Aboab J, Buisson CB, Brochard L. Transcutaneous arterial carbon dioxide pressure monitoring in critically ill adult patients. Intensive Care Med 2006;32(2):309312

19. Clark JS, Votteri B, Ariagno RL, Cheung P, Eichhorn JH, Fallat RJ, et al. Noninvasive assessment of blood gases. Am Rev Respir Dis 1992;145(1):220-232.

20. Sanders MH, Kern NB, Costantino JP, Stiller RA, Strollo PJ Jr, Studnicki KA, et al. Accuracy of end-tidal and transcutaneous $\mathrm{P}_{\mathrm{CO}_{2}}$ monitoring during sleep. Chest 1994;106(2):472-483.

This article is approved for Continuing Respiratory Care Education credit. For information and to obtain your CRCE

(free to AARC members) visit

RCJournal.com

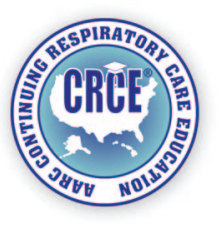

